\title{
Pelanggaran Prinsip Kerja Sama dan Prinsip Kesantunan Berbahasa Percakapan dalam Acara "Mata Najwa"
}

\author{
Nur Rahmawati \\ Universitas Indraprasta PGRI \\ Jalan Nangka No. 58 C/TB. Simatupang, Tanjung Barat, Jakarta Selatan 12530 \\ nurrahmawati95@gmail.com
}

\begin{abstract}
This study aims to determine the violation of the principle of cooperation, violation of the principle of politeness in language, the purpose of violating the principle of cooperation and the principle of politeness in conversational language in the "Mata Najwa" program. The data were obtained from the video show "Mata Najwa" episode July 2020. This writing approach is descriptive qualitative with the observation method with advanced techniques, namely the documentation technique, the free to engage proficient listening technique, and the note-taking technique. The results of this study showed that there were quite a lot of violations of the principle of cooperation and the principle of politeness in conversational language in the "Mata Najwa" program. Found violating the principle amounted to 65 data, 34 violations of the principle of cooperation and 31 violations of the principle of politeness. Violations of the principle of cooperation consist of maxim of quantity, maxim of quality, maxim of relevance, maxim of method, and maxim of combination of relevance and quantity. The most violations of the principle of cooperation were the maximum combined relevance and quantity of 13 data. The principle of modesty consists of a maxim of wisdom, a maxim of generosity, a maxim of praise, a maxim of humility, and a maxim of wisdom and praise combined. The most violations of the principle of politeness are the maxims of wisdom as many as 25 data. The purpose of violating the principles of cooperation and the principle of politeness consists of the goals of representative acts, directive acts, and expressive acts. The purpose of most violations of the principle of cooperation is the purpose of representative action by reason of providing explanations or information. The purpose of violating the principle of most modesty is the goal of directive action by reason of satire.
\end{abstract}

Keywords: Violation, Principle of Cooperation, Principle of Politeness, Mata Najwa

\begin{abstract}
Abstrak
Penelitian ini bertujuan untuk mengetahui pelangaran prinsip kerja sama, pelanggaran prinsip kesantunan berbahasa, tujuan pelanggaran prinsip kerja sama dan prinsip kesantunan berbahasa percakapan dalam acara "Mata Najwa". Data diperoleh dari video acara "Mata Najwa" episode Juli 2020. Pendekatan penelitian ini adalah deskriptif kualitatif dengan metode simak dengan teknik lanjutan yaitu teknik dokumentasi, teknik simak bebas libat cakap, dan teknik catat. Hasil penelitian menunjukkan bahwa pelanggaran prinsip kerja sama dan prinsip kesantunan berbahasa percakapan dalam acara "Mata Najwa" yang terjadi cukup banyak. Tuturan yang ditemukan melanggar prinsip berjumlah 65 data, 34 pelanggaran prinsip kerja sama dan 31 pelanggaran prinsip kesantunan. Pelanggaran prinsip kerja sama terdiri dari maksim kuantitas, maksim kualitas, maksim relevansi, maksim cara, dan maksim gabungan relevansi dan kuantitas. Pelanggaran prinsip kerja sama terbanyak adalah maksim gabungan relevansi dan kuantitas sebanyak 13 data. Prinsip kesantunan terdiri dari maksim kebijaksanaan, maksim kedermawanan, maksim pujian, maksim rendah hati, dan maksim gabungan kebijaksanaan dan pujian. Pelanggaran prinsip kesantunan terbanyak adalah maksim kebijaksanaan sebanyak 25 data. Tujuan pelanggaran prinsip kerja sama dan prinsip kesantunan terdiri dari tujuan tindak representatif, tindak direktif, dan tindak ekspresif. Tujuan pelanggaran prinsip kerja sama terbanyak adalah tujuan tindak representatif dengan alasan
\end{abstract}


memberikan penjelasan atau informasi. Tujuan pelanggaran prinsip kesantunan terbanyak adalah tujuan tindak direktif dengan alasan menyindir.

Kata kunci: Pelanggaran, Prinsip Kerja Sama, Prinsip Kesantunan, Mata Najwa

\section{PENDAHULUAN}

Suatu komunikasi dalam sebuah percakapan dikatakan berjalan dengan baik apabila tidak terjadi salah penafsiran oleh mitra tutur. Keith Allan (dalam Rahardi, 2005:52) mengemukakan bahwa bertutur adalah kegiatan yang berdimensi sosial. Kegiatan sosial dapat berlangsung baik apabila para peserta pertuturan itu semuanya terlibat aktif di dalam proses bertutur tersebut. Apabila terdapat satu atau lebih pihak yang tidak terlibat aktif dalam kegiatan bertutur dapat dipastikan pertuturan itu tidak dapat berjalan lancar.

Komunikasi akan berjalan baik apabila memenuhi prinsip kerja sama dan prinsip kesantunan berbahasa. Prinsip kerja sama merupakan sebuah prinsip dengan tujuan percakapan menjadi kooperatif. Terjadi komunikasi dua arah yang jelas, tanpa hambatan, tanpa adanya permasalahan dalam percakapan tersebut. Dalam hal ini, agar pesan yang disampaikan dapat diterima dengan baik, perlu adanya suatu kerja sama, yang disebut prinsip kerja sama percakapan. Grice (dalam Wijana dan Rohmadi, 2009:42) mengemukakan bahwa dalam rangka melaksanakan prinsip kerja sama, setiap penutur haruslah memenuhi 4 maksim percakapan (conversational maxim), yaitu maksim kuantitas, maksim kualitas, maksim relevansi, dan maksim pelaksanaan.

Penjelasan mengenai maksim yang ada di prinsip kerja sama: 1) Maksim kuantitas menghendaki setiap peserta pertuturan memberikan kontribusi yang secukupnya atau sebanyak yang dibutuhkan oleh lawan bicaranya. 2) Maksim kualitas mewajibkan setiap peserta percakapan mengatakan hal yang sebenarnya. Kontribusi peserta percakapan hendaknya didasarkan pada bukti-bukti yang memadai. Apabila patuh pada prinsip ini, jangan pernah mengatakan sesuatu yang diyakini bahwa itu kurang benar atau tidak benar. 3) Maksim relevansi mengharuskan setiap peserta percakapan memberikan kontribusi yang relevan dengan masalah pembicaraan. 4) Maksim pelaksanaan mengharuskan setiap peserta percakapan berbicara secara langsung, tidak kabur, tidak taksa, dan tidak berlebihlebihan, serta runtut.

Selain harus memenuhi prinsip kerja sama, sebuah percakapan hendaknya memenuhi prinsip kesantunan berbahasa. Sebagai diri yang menjadi bagian masyarakat yang memiliki tingkat keberagaman yang cukup tinggi, maka diperlukan keharmonisan sosial sebagai perwujudan dari kepekaan untuk saling memahami dan mengerti perasaan masing-masing yang dapat dirumuskan dalam wujud simpati. Prinsip sopan santun dalam bertutur merupakan bagian dari hal yang harus dipertimbangkan penutur dalam bertutur. Penutur sering tidak mementingkan hal tersebut, begitu juga dengan mitra tutur kurang memerhatikan prinsip sopan santun.

Maksim-maksim dalam prinsip kesantunan berbahasa meliputi: 1) Maksim Kearifan/Kebijaksanaan (Tact Maxim), yaitu peserta petuturan hendaknya 
berpegang pada prinsip untuk selalu mengurangi keuntungan dirinya sendiri dan memaksimalkan keuntungan pihak lain dalam kegiatan bertutur. 2) Maksim Kedermawanan (Generosity Maxim), yaitu penutur diharapkan dapat mengurangi keuntungan bagi dirinya sendiri dan memaksimalkan keuntungan bagi pihak lain (Rahardi, 2005: 61). 3) Maksim Pujian/Penghargaan (Approbation Maxim), yaitu orang akan dapat dianggap santun apabila dalam bertutur selalu berusaha memberikan penghargaan kepada pihak lain. Dengan maksim ini, diharapkan agar para peserta pertuturan tidak saling mengejek, saling mencaci, atau saling merendahkan pihak yang lain. 4) Maksim Kerendahan Hati/Kesederhanaan (Modesty Maxim), yaitu peserta tutur diharapkan dapat besikap rendah hati dengan cara mengurangi pujian terhadap dirinya sendiri. 5) Maksim Kesepakatan/ Kecocokan (Aggrement Maxim), maksim kesepakatan seringkali disebut dengan maksim kecocokan. Di dalam maksim ini ditekankan agar para peserta tutur dapat saling membina kecocokan atau kesepakatan di dalam kegiatan bertutur. Apabila terdapat kemufakatan atau kecocokan antara diri penutur dan mitra tutur dalam kegiatan bertutur, masing- masing dari mereka akan dapat dikatakan bersikap santun (Rahardi, 2005: 64). 6) Maksim Simpati, yaitu peserta tutur dapat memaksimalkan sikap simpati antara pihak yang satu dengan pihak lainnya. Sikap antipati terhadap salah seorang peserta tutur akan dianggap sebagai tindakan tidak santun. Orang yang bersikap sinis terhadap pihak lain, akan dianggap sebagai orang yang tidak tahu sopan santun di dalam masyarakat (Rahardi, 2005: 65).

Yule (2014:3) menjelaskan bahwa "pragmatic" adalah makna yang disampaikan oleh penutur (atau penulis) dan ditafsirkan oleh pendengar (atau pembaca). Artinya pragmatik melihat bahasa berdasarkan penutur dan mitra tutur. Dari penjelasan ini dapat kita pahami bahwa dalam sebuah tuturan harus ada kesepahaman dan pematuhan prinsip agar terjadi komunikasi yang baik. Penjelasan lainnya mengenai pragmatik adalah "Telaah mengenai hubungan antara bahasa dan konteks yang tergramatisasikan atau disandikan dalam struktur suatu bahasa (Tarigan, 2009:30).

Acara televisi tidak hanya memiliki fungsi untuk memberikan hiburan kepada masyarakat, melainkan juga memberikan informasi dan informasi yang bermanfaat bagi masyarakat. Menurut Effendy (2000: 149-150), televisi mempunyai fungsi sebagai berikut: 1) fungsi informasi, 2) fungsi pendidikan, 3) fungsi menghibur, dan 4) fungsi mempengaruhi. Untuk memaksimalkan fungsi tersebut, dibutuhkan proses komunikasi yang baik dalam setiap acara yang ditayangkan di televisi. Oleh karena itu, gelar wicara yang baik harus memenuhi prinsip kerja sama dan prinsip kesantunan berbahasa.

"Mata Najwa" merupakan suatu acara dialog antara Najwa Shihab dengan nara sumbernya dengan topik yang diangkat berbeda-beda setiap episodenya. Menggunakan bahasa Indonesia yang formal dan diisi oleh narasumber dari berbagai kalangan mulai dari pejabat hingga rakyat biasa sekali pun. Acara "Mata Najwa" saat ini ditayangkan di Trans 7.

Dalam bertutur, manusia pastilah mempunyai tujuan. Tujuan yang dimaksud oleh penutur berupa pemberian informasi kepada lawan tutur. Darjowidjojo (2003: 98) mengemukakan bahwa tujuan tuturan terkait dengan unsur-unsur sebagai berikut: 1) Tindak Representatif, menurut Levinson (dalam 
Rani, Arifin, dan Martutik, 2006: 241) tindak representatif atau tindak tutur asertif adalah tindak tutur menyampaikan proposisi yang benar. Hal itu berarti tindak tutur yang disampaikan oleh penutur lazimnya menghendaki respons dari mitra tutur. 2) Tindak Direktif, menurut Levinson dalam (Rani, Arifin, dan Martutik, 2006: 234) tindak direktif adalah tindak yang bermaksud menghasilkan efek melalui suatu tindakan oleh pendengar. Searle (dalam Rani, Arifin, dan Martutik, 2006: 234) mengartikan bahwa tindak direktif merupakan tindak yang berupa perintah atau permintaan, yakni agar penutur atau mitra tutur melakukan tindakan yang disebutkan di dalam tuturan itu. 3) Tindak Ekspresif, tindak ini dipakai oleh penutur bila ingin menyatakan keadaan psikologisnya mengenai sesuatu, misalnya menyatakan, terima kasih, belasungkawa, menyampaikan ucapan selamat, dan juga mengumpat (Dardjowidjojo, 2003: 96). Tujuan dari ekspresif adalah mengungkapkan atau mengutarakan sikap psikologis penutur terhadap keadaan yang terjadi.

Pelanggaran prinsip kerja sama dan prinsip kesantunan berbahasa terjadi karena peserta tutur tidak mematuhi maksim yang terdapat dalam prinsip kerja sama dan kesantunan berbahasa. Setiap pelanggaran yang terjadi memiliki tujuan dan alasan pelanggaran yang dilakukan oleh peserta tutur.

\section{METODE}

Penelitian ini berbentuk deskriptif kualitatif. Metode yang digunakan untuk mengumpulkan data adalah metode simak. Teknik pengumpulan data yang digunakan antara lain: teknik dokumentasi, teknik simak bebas libat cakap, dan teknik catat. Fokus dalam penelitian ini adalah transkripsi percakapan yang terdapat dalam tayangan gelar wicara "Mata Najwa" episode Juli 2020. Subfokus penelitian pada penelitian ini adalah pelanggaran prinsip kerja sama, pelanggaran prinsip kesantunan berbahasa, dan tujuan pelanggaran prinsip kerja sama dan prinsip kesantunan berbahasa. Data dianalisis menggunakan tabel indikator pelanggaran prinsip kerja sama, prinsip kesantunan, tujuan dan alasan pelanggaran prinsip kerja sama dan prinsip kesantunan.

\section{HASIL DAN PEMBAHASAN}

\section{Hasil}

Di dalam penelitian ini tuturan yang melanggar prinsip kerja sama, prinsip kesantunan, tujuan dan alasan pelanggaran dari lima tayangan "Mata Najwa" episode Juli 2020 terdapat 34 pelanggaran prinsip kerja sama dan 31 pelanggaran prinsip kesantunan. Hasil analisis data disajikan dalam tabel berikut ini. 
Diskursus: Jurnal Pendidikan Bahasa Indonesia

Vol. 4, No. 1, April 2021, pp. 46-55

p-ISSN: 2615-4935

e-ISSN: 2615-4943

Tabel 1. Pelanggaran Prinsip Kerja Sama Percakapan dalam Acara "Mata Najwa"

\begin{tabular}{|c|c|c|c|c|c|}
\hline \multirow[t]{2}{*}{ No. } & $\begin{array}{c}\text { Jenis } \\
\text { Pelanggaran } \\
\end{array}$ & \multirow[t]{2}{*}{$\begin{array}{c}\text { Tujuan } \\
\text { Pelanggaran }\end{array}$} & \multirow[t]{2}{*}{$\begin{array}{c}\text { Alasan } \\
\text { Pelanggaran }\end{array}$} & \multirow[t]{2}{*}{ Frekuensi } & \multirow[t]{2}{*}{ Jumlah } \\
\hline & Maksim Tunggal & & & & \\
\hline \multirow[t]{2}{*}{1.} & Kuantitas & Representatif & $\begin{array}{l}\text { Memberi } \\
\text { penjelasan/infor } \\
\text { masi }\end{array}$ & 10 & 12 \\
\hline & & & Menegaskan & 2 & \\
\hline 2. & Kualitas & Representatif & $\begin{array}{l}\text { Memberi } \\
\text { penjelasan/infor } \\
\text { masi }\end{array}$ & 2 & 2 \\
\hline \multirow[t]{6}{*}{3.} & Relevansi & Representatif & $\begin{array}{l}\text { Memberi } \\
\text { penjelasan/infor } \\
\text { masi }\end{array}$ & 2 & 6 \\
\hline & & & Menegaskan & 1 & \\
\hline & & Direktif & Memberi saran & 1 & \\
\hline & & & Menunjukkan & 1 & \\
\hline & & Ekspresif & rasa tidak suka & & \\
\hline & & & Merayu & 1 & \\
\hline \multirow[t]{2}{*}{4.} & Cara/Pelaksanaan & Representatif & $\begin{array}{l}\text { Memberi } \\
\text { penjelasan/infor } \\
\text { masi }\end{array}$ & 1 & 1 \\
\hline & & Jumlah & & 21 & \\
\hline \multirow[t]{2}{*}{ No. } & $\begin{array}{c}\text { Jenis } \\
\text { Pelanggaran }\end{array}$ & $\begin{array}{c}\text { Tujuan } \\
\text { Pelanggaran }\end{array}$ & $\begin{array}{c}\text { Alasan } \\
\text { Pelanggaran }\end{array}$ & Frekuensi & Jumlah \\
\hline & Maksim Ganda & & & & \\
\hline \multirow[t]{2}{*}{1.} & $\begin{array}{l}\text { Relevansi dan } \\
\text { Kuantitas }\end{array}$ & Representatif & $\begin{array}{l}\text { Memberi } \\
\text { penjelasan/infor } \\
\text { masi }\end{array}$ & 12 & 13 \\
\hline & & $\begin{array}{l}\text { Direktif } \\
\text { Jumlah }\end{array}$ & Memberi saran & 1 & \\
\hline
\end{tabular}

Tabel 2. Pelanggaran Prinsip Kesantunan Percakapan dalam Acara "Mata Najwa"

\begin{tabular}{|c|c|c|c|c|c|}
\hline No. & $\begin{array}{c}\text { Jenis } \\
\text { Pelanggaran } \\
\text { Maksim } \\
\text { Tunggal } \\
\end{array}$ & $\begin{array}{c}\text { Tujuan } \\
\text { Pelanggaran }\end{array}$ & $\begin{array}{c}\text { Alasan } \\
\text { Pelanggaran }\end{array}$ & Frekuensi & Jumlah \\
\hline \multirow{6}{*}{1.} & \multirow{6}{*}{$\begin{array}{l}\text { Kebijaksanaan/ } \\
\text { Kearifan }\end{array}$} & \multirow{6}{*}{ Direktif } & Menyindir & 13 & \multirow{6}{*}{25} \\
\hline & & & Menuduh & 1 & \\
\hline & & & Mengejek & 1 & \\
\hline & & & Memaksa & 1 & \\
\hline & & & Memojokkan & 7 & \\
\hline & & & Memberi saran & 1 & \\
\hline
\end{tabular}




\begin{tabular}{|c|c|c|c|c|c|}
\hline & & & Memberi penilaian & 1 & \\
\hline 2. & Kedermawanan & Direktif & Mengejek & 1 & 1 \\
\hline \multirow{2}{*}{3.} & \multirow{2}{*}{ Pujian } & \multirow{2}{*}{ Direktif } & Memojokkan & 1 & \multirow{2}{*}{2} \\
\hline & & & Meremehkan & 1 & \\
\hline \multirow[t]{2}{*}{4.} & Rendah hati & Ekspresif & $\begin{array}{l}\text { Menyombongkan } \\
\text { diri } \\
\text { Menyatakan rasa } \\
\text { tidak suka }\end{array}$ & $\begin{array}{l}1 \\
1\end{array}$ & \multirow[t]{2}{*}{2} \\
\hline & & Jumla & & 30 & \\
\hline \multirow{2}{*}{ No. } & $\begin{array}{c}\text { Jenis } \\
\text { Pelanggaran } \\
\end{array}$ & \multirow{2}{*}{$\begin{array}{c}\text { Tujuan } \\
\text { Pelanggaran }\end{array}$} & \multirow{2}{*}{$\begin{array}{c}\text { Alasan } \\
\text { Pelanggaran }\end{array}$} & \multirow[t]{2}{*}{ Frekuensi } & \multirow[t]{2}{*}{ Jumlah } \\
\hline & Maksim Ganda & & & & \\
\hline \multirow[t]{2}{*}{1.} & $\begin{array}{l}\text { Kebijaksanaan } \\
\text { dan pujian }\end{array}$ & Direktif & Menyindir & 1 & 1 \\
\hline & & \multicolumn{2}{|c|}{ Jumlah } & \multicolumn{2}{|c|}{1} \\
\hline
\end{tabular}

\section{Pembahasan}

Deskripsi informasi tentang penelitian ini adalah acara "Mata Najwa" yang dipandu oleh Najwa Shihab dan tayang di Trans 7 edisi Bulan Juli 2020 setiap hari Rabu. Selain tayang di televise acara "Mata Najwa" juga diunggah di laman youtube "Narasi Newsroom". Judul tayangan dari masing-masing episode "Mata Najwa” Juli 2020 yaitu: "Di Balik Jengkelnya Jokowi", "Menagih Wakil Rakyat", "Kita Belum Menang", Buron Istimewa", dan "Kasus-Kasus Misterius".

Dari pemaparan tabel hasil penelitian dapat dijelaskan bahwa terjadi pelanggaran prinsip kerja sama sebanyak 34 data dan prinsip kesantunan berbahasa sebanyak 31 data. Pelanggaran yang terjadi memiliki alasan dan tujuan pelanggaran yang beragam.

Pelanggaran prinsip kerja sama yang terjadi dalam acara "Mata Najwa" episode Juli 2020 meliputi maksim tunggal dan maksim ganda. Maksim tunggal terdiri dari: 1) Maksim kuantitas 12 data, 2) Maksim kualitas 2 data, 3) Maksim relevansi 6 data, 4) Maksim cara 1 data. Maksim ganda terdiri dari: 1) Maksim relevansi dan kuantitas 13 data.

Pelanggaran prinsip kesantunan yang terjadi dalam acara "Mata Najwa" episode Juli 2020 meliputi maksim tunggal dan maksim ganda. Maksim tunggal terdiri dari: 1) Maksim kebijaksanaan 25 data, 2) Maksim kedermawanan 1 data, 3) Maksim Pujian 2 data, 4) Maksim Rendah Hati 2 data. Maksim ganda terdiri dari: 1) Maksim kebijaksanaan dan pujian 1 data.

Pelanggaran prinsip kerja sama dan prinsip kesantunan berbahasa yang terjadi dalam acara "Mata Najwa" memiliki tujuan dan alasannya masing-masing. Berdasarkan penelitian, ditemukan tujuan pelanggaran prinsip kerja sama tunggal dan ganda yaitu: 1) Representatif 30 data, 2) Direktif 2 data, 3) Ekspresif 2 data. Alasan pelanggaran prinsip kerja sama antara lain: 1) Memberi penjelasan atau informasi 27 data, 2) Menegaskan 3 data, 3) Memberi saran 2 data, 4) Menunjukkan rasa tidak suka 1 data, 5) Merayu 1 data. Ditemukan tujuan pelanggaran prinsip kesantunan tunggal dan ganda yaitu: 1) Direktif 29 data, 2) Ekspresif 2 data. Alasan 
pelanggaran prinsip kesantunan antara lain: 1) Menyindir 14 data, 2) Menuduh 1 data, 3) Mengejek 2 data, 4) Memaksa 1 data, 5) Memojokkan 8 data, 6) Memberi saran 1 data, 7) Memberi penilaian 1 data, 8) Meremehkan 1 data, 9) Menyombongkan diri 1 data, 10) Menyatakan rasa tidak suka 1 data.

Contoh tuturan yang melanggar maksim kuantitas dengan tujuan tindak representatif dan alasan pelanggaran berupa memberikan penjelasan (Maksim tunggal) yaitu:

(1) Konteks : Percakapan terjadi antara pembawa acara dan Pak Moeldoko. Najwa bertanya kepada Pak Moel apakah wajar Pak Jokowi marah. Selain memberi jawaban, Pak Moel juga memberikan pendapat yang tidak dipinta oleh Najwa.

Najwa : Wajar Pak Jokowi marah?

Moeldoko : Wajar

Najwa : Wajar

Moeldoko : Seorang pemimpin marah adalah sesuatu yang wajar,

kenapa? Pak Jokowi melihat proyeksi pertumbuhan ekonomi dunia yang sering dikatakan oleh UICD, oleh World Bank dan seterusnya. Sehingga situasi itu ya, perlu ditransformasi kepada bawahannya kepada pembantu-pembantunya.

(MataNajwa/DBJJ/PPKS/D6).

Percakapan (1) di atas adalah tuturan dengan pelanggaran maksim kuantitas. Pak Moeldoko (mitra tutur) melanggar maksim kuantitas karena memberikan informasi yang berlebihan dari apa yang dibutuhkan. Informasi yang berlebihan tersebut tampak pada tuturan ketika pembawa acara menayakan kepada Pak Moel "Wajar Pak Jokowi marah?", dan Pak Moel sudah menjawab "Wajar”. Namun, selanjutnya Pak Moeldoko memberikan penjelasan yang sebelumnya tidak dipinta atau ditanyakan oleh Najwa yang berisi "Seorang pemimpin marah adalah sesuatu yang wajar, kenapa? Pak Jokowi melihat proyeksi pertumbuhan ekonomi dunia...".

Pelanggaran maksim kuantitas yang dilakukan oleh Pak Moeldoko tersebut semata-mata karena memiliki tujuan dan alasan untuk memberikan penjelasan. Meskipun penjelasan yang disampaikan oleh Pak Moeldoko terlihat berlebihan dari yang dibutuhkan. Oleh karena itu, pelanggaran yang dilakukan oleh Pak Moeldoko adalah pelanggaran maksim kuantitas dengan tujuan tindak representatif dengan tujuan tuturan berupa memberikan penjelasan.

Contoh pelanggaran prinsip kerja sama maksim ganda contoh tuturan yang melanggar maksim relevansi dan kuantitas dengan tindak tujuan direktif dengan alasan memberi saran.

(2) Konteks

: Percakapan antara pembawa acara (Najwa) dan Pak Fahri Hamzah. Najwa bertanya apakah bisa wakil presiden melakukan fungsi itu? Kemudian dijawab oleh Pak Fahri dengan penjelasannya mengenai hal lain tentang kantor presiden. 


$\begin{array}{ll}\text { Najwa } & \text { Wakil presiden, KH. Ma'ruf Amin apakah bisa } \\ \text { Fahri } & \text { melakukan fungsi itu? } \\ & \text { Fungsinya Pak Kyai Ma'ruf ya kan, jangankan bahkan } \\ & \text { saya ada usul Pak Moeldoko tolonglah kosongkan itu } \\ & \text { kantor istana Wapres itu pindahkan Pak Ma'ruf itu ke } \\ & \text { kantornya Pak Jokowi. Ini setting lama, setting orde } \\ & \text { baru itu salah itu. Kok, wakil presiden dikasih istana } \\ & \text { khusus, pindah dia, dia itu anak buahnya presiden dan } \\ & \text { dia ngantor di kantornya presiden supaya setiap hari } \\ & \text { bisa ngomong sama presiden. Beliau orang tua yang } \\ & \text { senior, ketua majelis ulama bisa memberikan } \\ & \text { ketenangan kepada pak presiden supaya jangan ikut } \\ & \text { kepada kebijakan-kebijakan yang menyebabkan } \\ & \text { presiden berpihak dalam konflik kayak kemarin itu } \\ & \text { kasus HIP dan sebagainya itu harusnya presiden tidak } \\ & \text { usah ikut. Yang terakhir saya mohon maaf ya ini soal } \\ & \text { penjurubicaraan. Kita tahu Pak Jokowi itu kalau } \\ & \text { ngomong itu apa namanya ya dia ngga bisa } \\ & \text { mengentertain orang lah ya kan, tetapi karenanyalah } \\ & \text { pengambil alihan penjurubicaraan. } \\ & \text { Najwa/DBJJ/PPKS/D23). }\end{array}$

Percakapan (2) di atas merupakan contoh tuturan yang melanggar prinsip kerja sama ganda yaitu maksim relevansi dan kuantitas. Pelanggaran kedua maksim tersebut terjadi karena Pak Fahri memberikan kontribusi atau informasi yang tidak relevan dan berlebihan dari apa yang dibutuhkan oleh mitra tuturnya. Ketika ditanya oleh pembawa acara, apakah wakil presiden bisa menjalankan fungsi itu?. Namun dijawab oleh Pak Fahri panjang lebar tentang sarannya agar wakil presiden satu kantor dengan presiden, mengkritik presiden, dan hal lainnya yang tidak relevan dengan pertanyaan yang diberikan oleh Najwa. Penjelasan yang disampaikan oleh Pak Fahri pun berlebihan dari yang dibutuhkan.

Adapun tujuan dari tuturan yang melanggar maksim relevansi dan maksim kuantitas di atas adalah tujuan tindak direktif dan alasan pelanggaran untuk memberikan saran kepada pemerintah.

Contoh pelanggaran prinsip kesantunan yang melanggar maksim kebijaksanaan dengan tujuan tindak direktif dan alasan berupa menyindir (maksim tunggal) sebagai beikut.

(3) Konteks : Percakapan antara narasumber, Pak Fahri dan Pak Qodari. Pak Qodari menyampaikan pendapatnya tentang partai yang dipimpin oleh Pak Fahri ketika ia sedang menceritakan negara Amerika Serikat.

Fahri : Mengikuti apa yang dilakukan tahun 61 di Amerika Serikat, ini harus kuat Pak.

Qodari : Biasa kalau partai baru begitu cita-citanya, konsepnya. Ini partai baru.

Fahri $\quad$ : Bukan (Mata Najwa/DBJJ/PPKB/D4) 
Percakapan (3) di atas terdapat tuturan yang melanggar prinsip kesantunan maksim kebijaksanaan. Hal tersebut dapat dilihat dari tuturan yang disampaikan oleh Pak Qodari yang berisi pendapatnya tentang partai yang Pak Fahri pimpin. Saat Pak Fahri tengah bersemangat menyampaikan pendapatnya bahwa Indonesia misalnya bisa mencontoh hal yang terjadi di Amerika Serikat, justru Pak Qodari membalasnya dengan tuturan "Biasa kalau partai baru begitu cita-citanya, konsepnya. Ini partai baru." Tuturan tersebut segera dibantah oleh Pak Fahri "Bukan".

Tujuan pelanggaran maksim kebijaksanaan ini adalah tujuan tindak dierktif dengan alasan menyindir. Maksud dari tuturan yang disampaikan Pak Qodari adalah menyindir mitra tuturnya, yang sedang bersemangat dan sangat idealis karena partainya baru saja dibentuk. Maksim kebijaksanaan tidak membolehkan peserta tutur untuk memerikan kerugian untuk orang lain, salah satunya menyindir mitra tuturnya.

Contoh pelanggaran prinsip kesantunan maksim ganda yaitu kebijaksanaan dan maksim pujian secara bersamaan. Tujuan pelanggaran maksim ini adalah tindak direktif dengan alasan pelanggaran berupa menyindir sebagai berikut.

(4) Konteks : Percakapan antara narasumber acara Mata Najwa, Bonyamin dan Anita. Pak Bonyamin mengibaratkan mitra tuturnya, Anita levelnya seperti binatang yang berupa sindiran kepada mitra tuturnya itu.

Bonyamin : Saya sejak awal itu sebenarnya bahkan mengistilahkan mohon maaf Bu Anita, mengistilahkan ular kecil naga gitu kan. Bu Anita itu pada level ular kecil aja sebenarnya.

Anita : Jangan, saya juga ngga uler Pak.. Enak aja.

Bonyamin : Sebagian nggak kalau ayam, ayam ajalah.

Anita : Jangan dong

Bonyamin : Ayam anak sama ayam jago. Jadi artinya Bu Anita itu hanya

Anita : Udah manusia, manusia aja disebutnya Pak, jangan sebut jangan umpamakan dengan binatang dong

Bonyamin : Ya bagian kecil aja bagian kecil bukan bagian besar, buktinya ini tadi ternyata Pak Prasetio kenalnya lebih duluan dengan Pak Djoko Tjandra gitu lho Bu Anita belakangan gitu lho.

Anita : Silakan anda, jadi jangan memojokkan saya (Mata Najwa/ BI/ PPKB. D27)

Percakapan (4) di atas merupakan percakapan dengan tuturan yang melanggar dua maksim, yaitu maksim kebijaksanaan dan maksim pujian. Pelanggaran maksim ganda tersebut terjadi karena prserta tutur menimbulkan kerugian dan mengecam mitra tuturnya. Pak Bonyamin mengibaratkan lawan tuturnya berada pada level ular kecil dan ayam. Pelanggaran tersebut terlihat pada tuturan Pak Bonyamin “... mengistilahkan ular kecil naga gitu kan. Bu Anita itu pada level ular kecil aja sebenarnya" dan "Sebagian nggak, kalau ayam, ayam ajalah". Tentu saja tuturan yang disampaikan oleh Pak Bonyamin tersebut tidak 
diterima oleh mitra tuturnya, $\mathrm{Bu}$ Anita. Tuturan tersebut merugikan $\mathrm{Bu}$ Anita karena ia merasa tersindir dan tidak terima disamakan dengan level binatang.

Tujuan dari pelanggaran tuturan yang terjadi pada percakapan (4) di atas yaitu tujuan tindak direktif dengan alasan pelanggaran berupa menyindir. Pak Bonyamin tidak benar-benar menyatakan bahwa mitra tuturnya selevel dengan binatang, namun mengibaratkan mitra tuturnya untuk menyindir. Tuturan ini merugikan dan tidak diterima oleh mitra tuturnya, Bu Anita.

\section{SIMPULAN}

Berdasarkan ulasan pada hasil dan pembahasan dalam penelitian ini dapat disimpulkan bahwa terdapat 34 tuturan yang melanggar prinsip kerja sama dan 31 tuturan yang melanggar prinsip kesantunan berbahasa. Pelanggaran prinsip kerja sama meliputi maksim kuantitas, maksim kualitias, maksim relevansi, dan maksim cara. Pelanggaran prinsip kesantunan meliputi maksim kebijaksanaan, maksim kedermawanan, maksim pujian, dan maksim rendah hati. Tujuan pelanggaran prinsip kerja sama dan prinsip kesantunan berbahasa yaitu (a) tujuan tutur tindak representatif dengan alasan berupa: memberi penjelasan dan informasi, menegaskan, (b) tujuan tutur tindak direktif dengan alasan berupa: memberi saran, menyindir, menuduh, mengejek, memaksa, memojokkan, memberi penilaian, meremehkan, (c) tujuan tindak ekspresif dengan alasan berupa: menyombongkan diri, menyatakan rasa tidak suka.

\section{DAFTAR PUSTAKA}

Dardjowidjojo, S. (2003). Psikolinguistik pengantar pemahaman bahasa manusia. Jakarta: Obor.

Effendy, O. U. (2000). Ilmu komunikasi teori dan praktek. Bandung: PT Remaja Rosdakarya

Rahardi, K. (2005). Pragmatik kesantunan imperatif bahasa Indonesia. Jakarta: Erlangga

Rani, A., Arifin, B., \& Martutik. (2006). Analisis wacana sebuah kajian bahasa dalam pemakaian. Malang: Bayumedia Publishing

Tarigan, H. G. (2009). Pengajaran pragmatik. Bandung: Angkasa

Wijana, I. D. P., \& Rohmadi, M. (2009). Analisis wacana pragmatik kajian teori dan analisis. Surakarta: Yuma Pustaka

Yule, G. (2014). Pragmatik. Yogyakarta: Pustaka Pelajar 